in vivo $31: 1059-1064(2017)$

doi:10.21873/invivo.11170

\title{
The Contribution of MMP-8 Promoter Genotypes to Childhood Leukemia
}

\author{
JEN-SHENG PEI ${ }^{1 *}$, WEN-SHIN CHANG ${ }^{2 *}$, PEI-CHEN HSU ${ }^{1 *}$, YI-WEN HUNG ${ }^{3}$, \\ SHUN-PING CHENG ${ }^{4}$, CHIA-WEN TSAI ${ }^{2}$, DA-TIAN BAU ${ }^{2,5,6}$ and CHI-LI GONG ${ }^{7}$ \\ ${ }^{1}$ Department of Pediatrics, Taoyuan General Hospital, Ministry of Health and Welfare, Taoyuan, Taiwan, R.O.C.; \\ ${ }^{2}$ Terry Fox Cancer Research Laboratory, China Medical University Hospital, Taichung, Taiwan, R.O.C., \\ ${ }^{3}$ Department of Medicine Research, Taichung Veterans General Hospital, Taichung, Taiwan, R.O.C.; \\ ${ }^{4}$ Department of Physical Medicine and Rehabilitation, Taoyuan General Hospital, \\ Ministry of Health and Welfare, Taoyuan, Taiwan, R.O.C.; \\ ${ }^{5}$ Graduate Institute of Biomedical Sciences, China Medical University, Taichung, Taiwan, R.O.C.; \\ ${ }^{6}$ Department of Bioinformatics and Medical Engineering, Asia University, Taichung, Taiwan, R.O.C.; \\ ${ }^{7}$ Department of Physiology, China Medical University, Taichung, Taiwan, R.O.C.
}

\begin{abstract}
Background/Aim: Accumulated evidence has supported the notion that matrix metalloproteinase (MMP) genotypes are associated with the susceptibility of many types of cancers. However, few reports have studied the contribution of MMP genotypes to either diagnostic or prognostic potential in non-solid tumors such as leukemia. In this study, we firstly investigated the contribution of a polymorphism in the promoter region of MMP-8 (-799C/T) and two non-synonymous polymorphisms (Val436Ala and Lys460Thr) to childhood leukemia. Patients and Methods: In this study, 266 patients with childhood acute lymphoblastic leukemia (ALL) and 266 non-cancer control patients were collected and the genomic DNA was isolated from their peripheral blood. MMP-8 -799C/T, Val436Ala and Lys460Thr polymorphic genotypes of each subject were determined by the typical polymerase chain reactionrestriction fragment length polymorphism (PCR-RFLP). Results: The results showed that the three polymorphisms were not significantly associated with an increased risk of childhood ALL in the overall investigated population.
\end{abstract}

This article is freely accessible online.

*These Authors contributed equally to this study.

Correspondence to: Da-Tian Bau, Chi-Li Gong and Chia-Wen Tsai, Terry Fox Cancer Research Laboratory, China Medical University Hospital, 2 Yuh-Der Road, Taichung, 404 Taiwan, R.O.C. Tel: +886 422052121 Ext. 7534, e-mail: datian@mail.cmuh.org.tw; artbau2@gmail.com

Key Words: Age, childhood, gender, genotype, leukemia, $M M P-8$, polymorphism.
Furthermore, when the analyses were stratified by age and gender, no significant association between these genotypes and increased ALL risk was found. Conclusion: Our findings suggest that the polymorphisms at MMP-8 799C/T, Val436Ala and Lys460Thr may not play a major role in determining the personal susceptibility to childhood ALL in Taiwan.

In recent years, mounting evidence have suggested that genetic factors play a significant role in the development of childhood acute lymphoblastic leukemia (ALL). For example, Down syndrome and Fanconi anemia, which are both inherited genetic human diseases, have been found to be associated with an elevated risk of $\operatorname{ALL}(1,2)$. Additionally, genetic mutations in several cancer-related genes, such as p53, N-ras, and PHF6, have also been frequently identified among ALL patients (3). Furthermore, only a small fraction of children who are exposed to environmental factors go on to develop ALL, indicating the potential for a genetic predisposition to develop childhood ALL (4).

Matrix metalloproteinases (MMPs), a family of proteins regulating the aggravation of extracellular matrix and basement membranes (5), play an important role in cell proliferation, differentiation, apoptosis, invasion, migration, metastasis, angiogenesis and immune surveillance during carcinogenesis (6). Previous studies reported that functional polymorphisms of MMPs may determine the inter-individual differences of susceptibility to several types of cancer (7-11). In 2011, it was reported that patients with relatively overexpressed MMP protein pattern and homozygous for rare genotypes in $\mathrm{rs} 8113877 \mathrm{~T}>\mathrm{G}$ or $\mathrm{rs} 17576 \mathrm{~A}>\mathrm{G}$ of the $M M P-9$ gene were at highest risk of chronic lymphocytic leukemia 
in European adults (12). In 2014, a whole-exome sequencing analysis identified a novel mutation on MMP-8, G189D, and validated its association with acute megakaryoblastic leukemia in an adult patient (13). In 2015, in a study recruiting 778 Danish and German childhood ALL patients, rs3216144 and rs10502001 of MMP-7 were found to be associated with risk of relapse of childhood ALL (14). The above three papers are the few papers investigating the genetic contribution of MMPs to leukemia, and only the last one is for the childhood ALL.

Among the MMPs, MMP-8 is a collagen cleaver which is present in the connective tissues, and encoded by $M M P-8$ $(15,16)$. In literature, the $M M P-8-799 \mathrm{C} / \mathrm{T}$ genotype was associated with breast cancer (17) and the electrophoretic mobility shift assays revealed differences in nuclear protein binding to oligonucleotides representing the $-799 \mathrm{C} / \mathrm{T}$ genotype (18). In addition, the promoter constructs containing the CT and TT genotypes at the $-799 \mathrm{C} / \mathrm{T}$ had a $3-$ fold greater activity in chorion-like trophoblast cells compared to the constructs containing the C alleles (18). However, the role of $M M P-8$ genotypes were never examined in ALL, not to mention childhood ALL. The current study aimed at investigating the contribution of MMP-8 -799C/T, Val436Ala and Lys460Thr polymorphisms to the susceptibility of childhood ALL in a Taiwanese population.

\section{Materials and Methods}

Patients and controls. The protocol of the current study was approved by the Institutional Review Board of China Medical University Hospital, and written informed consent was obtained from one or both parents of all participants. Two hundred and sixtysix patients diagnosed with childhood ALL (all patients under 18 years of age) were recruited between 2005-2010 from the General Surgery outpatient clinics within the Pediatric Departments at the China Medical University Hospital and the National Taiwan University Hospital, Taiwan, Republic of China. All of the clinical characteristics of these patients, including their histological details, were identified by expert surgeons. All children voluntarily participated, completed a questionnaire with the help of their parents or guardians, and provided peripheral blood samples. The questionnaire recorded their disease history, diet and sleeping habit, and the disease history, diet, behavioral lifestyle and socioeconomic status of the parents. An equal number of age-matched non-cancer healthy volunteers were selected for use as a control group following initial random sampling from the Health Examination Cohort established from 2005 to 2010 as previously published (1921 ). The registered health practitioners in the hospital provided a multidisciplinary team approach of health assessment for the volunteers. Most of the volunteers underwent health examinations every 5 to 6 months. A total of 457 volunteers aged under 18 years were recruited into this study. They were cancer free by the age at diagnosis with the International Classification of Disease, ninth revision (ICD-9) codes (defined by World Health Organization). Finally, 266 participants were included for analysis in the study to match the population structure (number, age and gender) with our case population. The overall agreement rate in the study was above $85 \%$. Selected recorded characteristics of the subjects in case and control groups are summarized and compared in Table I.

Methodology of MMP-8 genotyping. Genomic DNA from peripheral blood of each participant was extracted aliquoted and stored as previously described (22-24). The primers for MMP-8 $-799 \mathrm{C} / \mathrm{T}$, Val436Ala and Lys460Thr polymorphisms were custom designed by our team (shown in Table II) and the genotyping polymerase chain reaction (PCR) cycling conditions via My Cycler (Biorad, Hercules, CA, USA) for $M M P-8$ were: one cycle at $94^{\circ} \mathrm{C}$ for $5 \mathrm{~min}$; 35 cycles of $94^{\circ} \mathrm{C}$ for $30 \mathrm{~s}, 57^{\circ} \mathrm{C}$ for $30 \mathrm{~s}$ and $72^{\circ} \mathrm{C}$ for $30 \mathrm{~s}$ and a final extension at $72^{\circ} \mathrm{C}$ for $10 \mathrm{~min}$ as previously published $(25,26)$.

Statistical analysis. Pearson's Chi-square test without Yates' correction or Fisher's exact test was used to compare the distribution of the $M M P-8$ genotypes between case and control groups. The associations between the $M M P-8$ polymorphisms and childhood ALL risk were estimated by computing odds ratios (ORs) as well as their $95 \%$ confidence intervals (CIs) from unconditional logistic regression analysis with the adjustment for possible confounding factors if needed.

\section{Results}

Basic characteristics compared between childhood ALL patient and control groups. The frequency distributions of the characteristics for 266 childhood ALL cases and 266 controls are summarized and compared in Table I. No difference was found between the two groups as for age and gender since we have matched them very well $(p>0.05)$ (Table I).

Association analysis of MMP-8 genotypes at $-799 C / T$, Val436Ala and Lys460Thr with childhood ALL risk. The distributions of genetic frequencies for the $M M P-8$ polymorphisms for the childhood ALL patients and controls are presented and compared in Table III. First, there were no CT or CC genotypes at MMP- 8 Val436Ala among either the cases or the controls. That is to say, all the subjects were of TT genotype at MMP- 8 Val436Ala (Table III, lowest part). Second, the ORs with adjusting those possible confounding factors (age and gender) for the people carrying variant CT and TT genotypes at $M M P-8$ promoter $-799 \mathrm{C} / \mathrm{T}$ were 0.88 $(95 \% \mathrm{CI}=0.63-1.21, p=0.4403)$ and $0.79(95 \% \mathrm{CI}=0.49-1.35$, $p=0.5420$ ) respectively, compared to those carrying the CC wild-type genotype (Table II, upper part). The $p$-value for trend was not significant $(p=0.6832)$ (Table II). In the dominant model (CT plus TT versus $\mathrm{CC}$ ), the association between $M M P-8$ promoter $-799 \mathrm{C} / \mathrm{T}$ polymorphism and the risk for childhood leukemia was still not statistically significant (adjusted $\mathrm{OR}=0.82,95 \% \mathrm{CI}=0.61-1.23, p=0.3859$ ) (Table III, upper part). Last, a very small percentage of Taiwanese children were of heterozygous variant AC genotype at MMP-8 Lys460Thr $(0.8 \%$ and $1.1 \%$ in childhood ALL patient and control groups, respectively) and there was 
Pei et al: $M M P-8$ Genotype in Leukemia

Table I. Distribution of selected demographics of the 266 childhood ALL patients and the 266 matched controls.

\begin{tabular}{|c|c|c|c|c|c|c|c|}
\hline \multirow[t]{2}{*}{ Characteristics } & \multicolumn{3}{|c|}{ Controls $(n=266)$} & \multicolumn{3}{|c|}{ Patients $(n=266)$} & \multirow[t]{2}{*}{$p$-Value } \\
\hline & $\mathrm{n}$ & $\%$ & Mean (SD) & $\mathrm{n}$ & $\%$ & Mean (SD) & \\
\hline Age at onset (years old) & & & $8.3(4.8)$ & & & $7.0(4.4)$ & $0.6483^{\mathrm{a}}$ \\
\hline Gender & & & & & & & $1.0000^{\mathrm{b}}$ \\
\hline Male & 148 & $55.6 \%$ & & 148 & $55.6 \%$ & & \\
\hline Female & 118 & $44.4 \%$ & & 118 & $44.4 \%$ & & \\
\hline
\end{tabular}

aBased on Student's $t$-test; bbased on Chi-square test; SD: standard deviation.

Table II. Primer sequences, specific restriction enzymes, fragment sizes of the PCR products after digestion according to their allelic genotypes.

\begin{tabular}{llccc}
\hline $\begin{array}{l}\text { Polymorphism } \\
\text { (rs number) }\end{array}$ & $\begin{array}{l}\text { Primer } \\
\text { sequences }\end{array}$ & $\begin{array}{c}\text { Restriction } \\
\text { enzyme }\end{array}$ & $\begin{array}{c}\text { SNP } \\
\text { sequence }\end{array}$ & $\begin{array}{c}\text { DNA fragment } \\
\text { size (bp) }\end{array}$ \\
\hline $\begin{array}{l}\text { C-799T } \\
\text { (rs11225395) }\end{array}$ & F: 5'-CCATCTTCACATAGCCTTGG-3' & Sfc I & T & 285 bp \\
Lys460Thr & R: 5'-CCTTGTCTTCTGCCTGTGAA-3 & C & $172+113$ bp \\
(rs35866072) & F: 5'-GGATTACAGGCATTAGCCAC-3' & Nla & A & $332 \mathrm{bp}$ \\
Val436Ala & R: 5'-CGAAAATGCATGCTGAACTTCC-3' & Cbs I & C & $245+87$ bp \\
(rs34009635) & F: 5'-GGATTACAGGCATTAGCCAC-3' & & T & $162+102$ bp \\
\hline
\end{tabular}

*F and $\mathrm{R}$ indicate forward and reverse primers, respectively.

no association between MMP-8 Lys460Thr AC genotypes and the risk for childhood ALL (adjusted $\mathrm{OR}=0.73$, 95\% CI $=0.22-3.87, p=0.6532$ ) (Table III, medium part).

Association of MMP-8 allelic types at -799C/T, Val436Ala and Lys460Thr and childhood ALL risk. Supporting the findings in Table III, there is no differential distribution of allelic frequencies between the childhood ALL patient and control groups as for the $M M P-8$ promoter $-799 \mathrm{C} / \mathrm{T}$ or Lys460Thr (Table IV). In detail, the adjusted OR for the subjects carrying the $\mathrm{T}$ allele at $M M P-8$ promoter $-799 \mathrm{C} / \mathrm{T}$ was 0.87 (95\% CI $=0.67-1.26, p=0.3869)$, compared to those carrying the $\mathrm{C}$ wild-type allele (Table IV, upper part). As for the allelic frequencies at MMP-8 Val436Ala and Lys460Thr polymorphic sites, there was no association between their genotypes and increased risk of childhood ALL (Table IV, medium and lower parts).

\section{Discussion}

MMPs play an important role in regulating the extracellular matrix components and carcinogenesis. In the literature, the genotypes of SNPs at promoter region of many $M M P$ genes were found to be associated with the risk of several types of cancer (7-11). However, the papers investigating the polymorphisms of MMPs as risk factors for childhood ALL are lacking, except of the whole-genome study that found that rs3216144 and rs10502001 of MMP-7 were associated with risk of relapse of childhood ALL (14). In that work, the samples were composed of 778 Danish and German children, all of whom were Caucasian. The authors examined as many as 25,000 to 34,000 preselected polymorphic sites to identify the relapse risk of these children. Among the polymorphic sites they investigated, rs3216144 and rs10502001 of MMP-7 were the two with the highest significant association ( $p=6.0^{*} 10^{-6}$ in combined cohorts) (14). These findings support the idea that MMPs may play an important role in carcinogenesis, and the genomic markers on $M M P s$ can serve as valuable predictive biomarkers for the development or reoccurrence of childhood ALL.

MMP-8 plays an important role in the development of ALL. Early in the twentieth century, MMP-8 was found to be highly expressed in Jurkat $\mathrm{T}$ leukemia cells, which was closely related to the suppression of invasiveness in $\mathrm{T}$ cells and could be down-regulated by genistein (27). In animal models, the mutant mice deficient in MMP-8 were more susceptible to develop skin cancer $(28,29)$, which strongly suggested that MMP-8 may play a protective role against the development of cancers. From the viewpoint of genomic study, some positive epidemiological findings reported that genotypes of promoter 
in vivo $31: 1059-1064(2017)$

Table III. Distributions of matrix metalloproteinase-8 (MMP-8) genotypic frequencies among childhood ALL cases and controls.

\begin{tabular}{|c|c|c|c|c|}
\hline & Cases $(\%)$ & Controls $(\%)$ & Adjusted OR $(95 \% \mathrm{CI})^{\mathrm{a}}$ & $p$-Value ${ }^{\mathrm{b}}$ \\
\hline \multicolumn{5}{|l|}{$-799 \mathrm{C} / \mathrm{T}$} \\
\hline CC (wildtype) & $139(52.3)$ & $129(48.5)$ & 1.00 (reference) & \\
\hline $\mathrm{CT}$ & $98(36.8)$ & $105(39.5)$ & $0.88(0.63-1.21)$ & 0.4403 \\
\hline $\mathrm{TT}$ & $29(10.9)$ & $32(12.0)$ & $0.79(0.49-1.35)$ & 0.5420 \\
\hline $\mathrm{CT}+\mathrm{TT}$ & $127(47.7)$ & $137(51.5)$ & $0.82(0.61-1.23)$ & 0.3859 \\
\hline \multicolumn{5}{|l|}{$\begin{array}{l}p_{\text {trend }} \\
\text { Lys460Thr }\end{array}$} \\
\hline AA (wildtype) & $264(99.2)$ & $263(98.9)$ & 1.00 (reference) & \\
\hline $\mathrm{AC}$ & $2(0.8)$ & $3(1.1)$ & $0.73(0.22-3.87)$ & 0.6532 \\
\hline $\mathrm{CC}$ & $0(0.0)$ & $0(0.0)$ & -- & \\
\hline \multicolumn{5}{|l|}{ Val436Ala } \\
\hline TT (wildtype) & $266(100.0)$ & $266(100.0)$ & 1.00 (reference) & \\
\hline $\mathrm{CT}$ & $0(0.0)$ & $0(0.0)$ & -- & \\
\hline $\mathrm{CC}$ & $0(0.0)$ & $0(0.0)$ & -- & \\
\hline
\end{tabular}

OR: Odds ratio; CI: confidence interval. ${ }^{a}$ Data has been adjusted with confounding factors include age and gender. ${ }^{b}$ Based on Chi-square test without Yates' correction or Fisher's exact test; * $p<0.05$.

Table IV. Allelic frequencies for matrix metalloproteinase-8 (MMP-8) polymorphisms among childhood ALL cases and controls.

\begin{tabular}{lccc}
\hline $\begin{array}{l}\text { Polymorphic site } \\
\text { Allele }\end{array}$ & $\begin{array}{c}\text { Cases }(\%) \\
\mathrm{N}=532\end{array}$ & $\begin{array}{c}\text { Controls }(\%) \\
\mathrm{N}=532\end{array}$ & $\begin{array}{c}\text { Adjusted OR } \\
(95 \% \mathrm{CI})^{\mathrm{a}}\end{array}$ \\
\hline $\begin{array}{l}\text { C-799T } \\
\text { Allele C }\end{array}$ & $376(70.7)$ & $363(68.2)$ & 1.00 (reference) \\
Allele T & $156(29.3)$ & $169(31.8)$ & $0.87(0.67-1.26)$ \\
Lys460Thr & $530(99.6)$ & $529(99.4)$ & 1.00 (reference) \\
Allele A & $2(0.4)$ & $3(0.6)$ & $0.68(0.24-4.31)$ \\
Allele C & $532(100.0)$ & $532(100.0)$ & 1.00 (reference) \\
Val436Ala & $0(0.0)$ & $0(0.0)$ & -- \\
Allele T & & & 0.6540 \\
Allele C & & &
\end{tabular}

OR: Odds ratio; CI: confidence interval. a Data has been adjusted with confounding factors include age, gender and smoking status. ${ }^{\mathrm{b}} \mathrm{Based}$ on Chisquare test without Yates' correction or Fisher's exact test; * $p<0.05$.

regions of other MMPs such as MMP-1 and MMP-9, may serve as promising markers for the prediction of lung cancer susceptibility and prognosis (30-32). From the molecular viewpoint, MMP-8 might increase cell adhesion by rearrangement of cytoskeleton actin, thus decreasing cell invasion (33). However, there were few epidemiological studies investigating the role of polymorphisms in $M M P-8$ to the susceptibility of cancers (34). In 2008, the $G$ variant allele at $M M P-8+17 \mathrm{C} / \mathrm{G}$ was found to be associated with a decreased risk of developing lung cancer, while there was no contribution of the particular polymorphism to the overall survival rates for the lung cancer patients (35). From the above information, in the present study, we firstly focused on the genotypes of specific $M M P-8$ polymorphisms among a Taiwanese population and assessed whether there was an association between the genotypes of the promoter region of MMP-8 (-799C/T) and two nonsynonymous polymorphisms (Val436Ala and Lys460Thr) with childhood ALL risk. The results showed that no significant association was observed and our findings suggest that these three $M M P-8$ polymorphisms may not play a critical role in mediating susceptibility to childhood ALL (Tables III and IV). Furthermore, when the analyses were stratified by age and gender, no significant association between these genotypes and childhood ALL risk was observed (data not shown). The phenotypic data including the expression levels of MMP-8 at mRNA or protein are not currently available for further analysis. The complete correlation of patient status, genotype and phenotype would be very helpful to understand the role of MMP-8 in childhood ALL development. 
In conclusion, this is the first study to investigate the contribution of genotypes at the $M M P-8$ promoter and nonsynonymous polymorphisms to childhood ALL development. Our results suggest that the genotypes of the promoter region $-799 \mathrm{C} / \mathrm{T}$ and nonsynonymous Val436Ala and Lys460 Thr at $M M P-8$, do not significantly confer susceptibility to Taiwan childhood ALL. Further studies elucidating the contribution of the genotypes of other members of MMPs to childhood ALL development are urgently needed.

\section{Conflicts of Interest}

All Authors declare no conflicts of interest.

\section{Acknowledgements}

The Authors are grateful to Hsin-Ting Li, Shiou-Ting Yen and Huai-Mei Hsu for their excellent technical assistance. All the participants in this study are appreciated. This study was supported mainly by Taoyuan General Hospital, Ministry of Health and Welfare, Taiwan, ROC to Dr Hsu and Dr. Pei (grant number: PTH10630) and partially by research grant from Taiwan Ministry of Health and Welfare Clinical Trial and Research Center of Excellence (MOHW106-TDU-B-212-113004). The funders had no role in the study design, data collection and analysis, decision to publish or preparation of the manuscript.

\section{References}

1 Zwaan CM, Reinhardt D, Hitzler J and Vyas P: Acute leukemias in children with Down syndrome. Hematol Oncol Clin North Am 24: 19-34, 2010.

2 Mathew CG: Fanconi anaemia genes and susceptibility to cancer. Oncogene 25: 5875-5884, 2006.

3 Szczepanski T, Harrison CJ and van Dongen JJ: Genetic aberrations in paediatric acute leukaemias and implications for management of patients. Lancet Oncol 11: 880-889, 2010

4 Kaatsch P: Epidemiology of childhood cancer. Cancer Treat Rev 36: $277-285,2010$

5 de Souza AP, Trevilatto PC, Scarel-Caminaga RM, Brito RB and Line SR: MMP-1 promoter polymorphism: association with chronic periodontitis severity in a Brazilian population. J Clin Periodontol 30: 154-158, 2003.

6 Egeblad $\mathrm{M}$ and Werb Z: New functions for the matrix metalloproteinases in cancer progression. Nat Rev Cancer 2: 161-174, 2002.

7 Tsai CW, Chang WS, Gong CL, Shih LC, Chen LY, Lin EY, Li $\mathrm{HT}$, Yen ST, Wu CN and Bau DT: Contribution of matrix metallopeptidase-1 genotypes, smoking, alcohol drinking and areca chewing to nasopharyngeal carcinoma susceptibility. Anticancer Res 36: 3335-3340, 2016.

8 Sun KT, Tsai CW, Chang WS, Shih LC, Chen LY, Tsai MH, Ji HX, Hsiao CL, Liu YC, Li CY and Bau DT: The Contribution of Matrix Metalloproteinase-1 Genotype to Oral Cancer Susceptibility in Taiwan. In Vivo 30: 439-444, 2016.

9 Lai CY, Chang WS, Hsieh YH, Hsu CM, Tsai CW, Chen AC, Wang $\mathrm{CH}$ and Bau DT: Association of tissue inhibitor of metalloproteinase-1 genotypes with lung cancer risk in Taiwan. Anticancer Res 36: 155-160, 2016.
10 Yu C, Zhou Y, Miao X, Xiong P, Tan W and Lin D: Functional haplotypes in the promoter of matrix metalloproteinase-2 predict risk of the occurrence and metastasis of esophageal cancer. Cancer Res 64: 7622-7628, 2004.

$11 \mathrm{Hu}$ Z, Huo X, Lu D, Qian J, Zhou J, Chen Y, Xu L, Ma H, Zhu J, Wei Q and Shen H: Functional polymorphisms of matrix metalloproteinase-9 are associated with risk of occurrence and metastasis of lung cancer. Clin Cancer Res 11: 5433-5439, 2005.

12 Casabonne D, Reina O, Benavente Y, Becker N, Maynadie M, Foretova L, Cocco P, Gonzalez-Neira A, Nieters A, Boffetta P, Middeldorp JM and de Sanjose S: Single nucleotide polymorphisms of matrix metalloproteinase 9 (MMP9) and tumor protein 73 (TP73) interact with Epstein-Barr virus in chronic lymphocytic leukemia: results from the European case-control study EpiLymph. Haematologica 96: 323-327, 2011.

13 Kim Y, Schulz VP, Satake N, Gruber TA, Teixeira AM, Halene S, Gallagher PG and Krause DS: Whole-exome sequencing identifies a novel somatic mutation in MMP8 associated with a $\mathrm{t}(1 ; 22)$-acute megakaryoblastic leukemia. Leukemia 28: 945 $948,2014$.

14 Wesolowska-Andersen A, Borst L, Dalgaard MD, Yadav R, Rasmussen KK, Wehner PS, Rasmussen M, Orntoft TF, Nordentoft I, Koehler R, Bartram CR, Schrappe M, SicheritzPonten T, Gautier L, Marquart H, Madsen HO, Brunak S, Stanulla M, Gupta R and Schmiegelow K: Genomic profiling of thousands of candidate polymorphisms predicts risk of relapse in 778 Danish and German childhood acute lymphoblastic leukemia patients. Leukemia 29: 297-303, 2015.

15 Hasty KA, Pourmotabbed TF, Goldberg GI, Thompson JP, Spinella DG, Stevens RM and Mainardi CL: Human neutrophil collagenase. A distinct gene product with homology to other matrix metalloproteinases. J Biol Chem 265: 1142111424, 1990 .

16 Devarajan P, Mookhtiar K, Van Wart H and Berliner N: Structure and expression of the cDNA encoding human neutrophil collagenase. Blood 77: 2731-2738, 1991.

17 Decock J, Long JR, Laxton RC, Shu XO, Hodgkinson C, Hendrickx W, Pearce EG, Gao YT, Pereira AC, Paridaens R, Zheng W and Ye S: Association of matrix metalloproteinase-8 gene variation with breast cancer prognosis. Cancer Res 67: 10214-10221, 2007.

18 Wang H, Parry S, Macones G, Sammel MD, Ferrand PE, Kuivaniemi H, Tromp G, Halder I, Shriver MD, Romero R and Strauss JF, 3rd: Functionally significant SNP MMP8 promoter haplotypes and preterm premature rupture of membranes (PPROM). Hum Mol Genet 13: 2659-2669, 2004.

19 Pei JS, Chang WS, Hsu PC, Tsai CW, Hsu CM, Ji HX, Hsiao CL, Hsu YN and Bau DT: The association of flap endonuclease 1 genotypes with the risk of childhood leukemia. Cancer Genomics Proteomics 13: 69-74, 2016.

20 Pei JS, Hsu PC, Chou AK, Tsai CW, Chang WS, Hsiao CL, Hsu YN, Cheng SP and Bau DT: Matrix metalloproteinase-1 genotype contributes to the risk of non-solid tumor in childhood leukemia. Anticancer Res 36: 5127-5132, 2016.

21 Lo WJ, Chang WS, Hsu HF, Ji HX, Hsiao CL, Tsai CW, Yeh SP, Chen CM and Bau DT: Significant association of interleukin-10 polymorphisms with childhood leukemia susceptibility in Taiwan. In Vivo 30: 265-269, 2016. 
22 Lai YL, Gong CL, Fu CK, Yueh TC, Tsai CW, Chang WS, Hsiao CL, Yen ST, Li HT, Jeng LB, Wang SC and Bau DT: The contribution of matrix metalloproteinase-1 genotypes to hepatocellular carcinoma susceptibility in Taiwan. Cancer Genomics Proteomics 14: 119-125, 2017.

23 Chang WS, Liao CH, Tsai CW, Hu PS, Wu HC, Hsu SW, Hsiao CL, Hsu CH, Hung YW and Bau DT: Association of enhancer of Zeste 2 (EZH2) genotypes with bladder cancer risk in Taiwan. Anticancer Res 36: 4509-4514, 2016.

24 Chuang CL, Wang CH, Hsu CH, Hsiao CL, Chen GL, Yen ST, Li HT, Chang WS, Tsai CW, Wang SC and Bau DT: Contribution of double-strand break repair gene Nijmegen breakage syndrome 1 genotypes, gender difference and smoking status to Taiwanese lung cancer. Anticancer Res 37: 2417-2423, 2017.

25 Hung YW, Tsai CW, Wu CN, Shih LC, Chen YY, Liu YF, Hung HS, Shen MY, Chang WS and Bau DT: The contribution of matrix metalloproteinase- 8 promoter polymorphism to oral cancer susceptibility. In Vivo 31: 585-590, 2017.

26 Shen TC, Hsia TC, Chao CY, Chen WC, Chen CY, Chen WC, Lin YT, Hsiao CL, Chang WS, Tsai CW and Bau DT: The contribution of MMP-8 promoter polymorphisms in lung cancer. Anticancer Res 37: 3563-3567, 2017.

27 Kim MH, Albertsson P, Xue Y, Nannmark U, Kitson RP and Goldfarb RH: Expression of neutrophil collagenase (MMP-8) in Jurkat T leukemia cells and its role in invasion. Anticancer Res 21: 45-50, 2001.

28 Balbin M, Fueyo A, Tester AM, Pendas AM, Pitiot AS, Astudillo A, Overall CM, Shapiro SD and Lopez-Otin C: Loss of collagenase- 2 confers increased skin tumor susceptibility to male mice. Nat Genet 35: 252-257, 2003.

29 Montel V, Kleeman J, Agarwal D, Spinella D, Kawai K and Tarin D: Altered metastatic behavior of human breast cancer cells after experimental manipulation of matrix metalloproteinase 8 gene expression. Cancer Res 64: 1687-1694, 2004.
30 Liu B, Yi M, Tang Y, Liu Q, Qiu H, Zou Y, Peng P, Zhang L, $\mathrm{Hu} \mathrm{C}$ and Yuan X: MMP-1 promoter polymorphism is associated with risk of radiation-induced lung injury in lung cancer patients treated with radiotherapy. Oncotarget 7: 70175-70184, 2016.

31 Bayramoglu A, Gunes HV, Metintas M, Degirmenci I, Mutlu F and Alatas F: The association of MMP-9 enzyme activity, MMP-9 C1562T polymorphism, and MMP-2 and -9 and TIMP-1, -2, -3, and -4 gene expression in lung cancer. Genet Test Mol Biomarkers 13: 671-678, 2009.

32 Liu L, Wu J, Wu C, Wang Y, Zhong R, Zhang X, Tan W, Nie S, Miao $X$ and Lin D: A functional polymorphism (-1607 1G-->2G) in the matrix metalloproteinase-1 promoter is associated with development and progression of lung cancer. Cancer 117: 51725181, 2011

33 Gutierrez-Fernandez A, Fueyo A, Folgueras AR, Garabaya C, Pennington CJ, Pilgrim S, Edwards DR, Holliday DL, Jones JL, Span PN, Sweep FC, Puente XS and Lopez-Otin C: Matrix metalloproteinase-8 functions as a metastasis suppressor through modulation of tumor cell adhesion and invasion. Cancer Res 68 : 2755-2763, 2008.

34 Gonzalez-Arriaga P, Lopez-Cima MF, Fernandez-Somoano A, Pascual T, Marron MG, Puente XS and Tardon A: Polymorphism $+17 \mathrm{C} / \mathrm{G}$ in matrix metalloprotease MMP8 decreases lung cancer risk. BMC Cancer 8: 378, 2008.
Received August 20, 2017

Revised September 14, 2017 Accepted September 19, 2017 